\title{
PENENTUAN HARGA OPSI DENGAN MODEL BLACK-SCHOLES MENGGUNAKAN METODE BEDA HINGGA CENTER TIME CENTER SPACE (CTCS)
}

\author{
Welgi Okta Irawan ${ }^{1}$, Media Rosha ${ }^{2}$, Dony Permana ${ }^{3}$ \\ Program Studi Matematika, FMIPA Universitas Negeri Padang \\ welgiokta01@gmail.com, mediarosha@gmail.com, donypermana27@gmail.com
}

\begin{abstract}
Stock options is defined as a contract between two parties or two person. The first parties is a buyer the contract has a right to buy or sell some stocks to the second parties. The contract contains price of selling and buying and a certain period of time when the transaction will be done. To generate a profit, investor have to calculate the fear price from the options how the options price can be bought or sold. A model of Black-Scholes is one of modelscan be used for calculating the option price. The model is partial differential equation form. One of methodsto find a solution of the model is a finite difference of Centre Time Centre Space (CTCS). This research aims to establish the option pricing formula with Black-Scholes Models with the solution using the CTCS finite difference method.After that, it is applied to determine the option price of Apple(AAPL) stocks from the American stock exchange (NASDAQ).The results is obtained bought optionprice and sold option price at 28 July 2017 are $\$ 5.2558$ and $\$ 0.9734$. The price of bought option in the market is $\$ 5.67$ (> $\$ 5.2558$ ), so investor should to sell bought option. Whereas the price of sold option in the market is $\$ 1.32$ (>\$0.9734), so investor should to sell sold option.
\end{abstract}

Keywords - Stock Option, Black-Sholes Model, Finite Difference Method, CTCS

\section{PENDAHULUAN}

Dalam menjalani aktivitas kehidupan sehari-hari, setiap orang memerlukan strategi untuk bertahan hidup. Strategi itu mencakup berbagai aspek bidang kehidupan, yaitu: bidang sosial, budaya, politik, ekonomi dan lain sebagainya. Dalam bidang ekonomi terdapat suatu strategi yang dinamakan dengan investasi.

Investasi adalah komitmen atas sejumlah dana atau sumber daya lainnya yang dilakukan pada saat ini, dengan tujuan memperoleh sejumlah keuntungan di masa datang [1]. Investasi disebut juga dengan penanaman modal. Orang yang melakukan kegiatan investasi disebut investor. Seorang investor dapat melakukan investasi dengan membeli sejumlah aset seperti emas, tanah, saham dan sebagainya. Investasi dalam bentuk aset bertujuan untuk memperoleh keuntungan dari kenaikan harga dimasa mendatang sebagai imbalan atas waktu dan resiko yang terkait dengan investasi tersebut.

Ada dua jenis investasi, yaitu investasi pada aset real (real assets) dan investasi pada aset finansial (financial assets). Investasi pada aset real adalah investasi dalam bentuk nyata, seperti tanah, emas, bangunan, mesin dan 
sebagainya. Sedangkan investasi pada aset finansial adalah investasi dalam bentuk surat berharga, seperti deposito, saham, obligasi dan sebagainya. Para investor dapat melakukan investasi pada aset real maupun pada aset finansial di pasar modal (capital market).

Martalena [2] pasar modal memiliki peran penting bagi perekonomian suatu negara karena pasar modal menjalankan dua fungsi, yaitu pertama sebagai sarana bagi yang membutuhkan dana atau perusahaan untuk mendapatkan dana dari investor. Kedua, pasar modal memiliki fungsi sebagai sarana bagi masyarakat untuk berinvestasi pada instrumen keuangan, seperti saham, obligasi, deposito dan sebagainya.

Di pasar modal, saham merupakan instrumen yang sering digunakan. Saham adalah surat berharga yang dijadikan sebagai bukti seorang investor memiliki hak kepemilikan atas suatu perusahaan. Sebagai salah satu instrumen investasi, saham juga memiliki resiko. Untuk meminimalkan resiko, investor dapat memperdagangkan instrumen derivatif. Instrumen derivatif adalah instrumen yang nilainya diturunkan atau berasal dari produk yang menjadi acuan pokok. Salah satu instrumen derivatif yaitu opsi.

Opsi adalah kontrak resmi yang memberikan hak (bukan kewajiban) untuk membeli atau menjual sejumlah tertentu instrumen yang dijadikan dasar kontrak pada harga tertentu dan dalam jangka waktu yang telah ditentukan. Ada dua jenis opsi yang dikenal, yaitu opsi beli (call option) dan opsi jual (put option). Opsi beli adalah opsi yang memberikan hak (bukan kewajiban) kepada pemegangnya untuk membeli sejumlah tertentu dari sebuah instrumen yang menjadi dasar kontrak tersebut dengan jumlah tertentu pada waktu dan harga yang telah ditentukan. Opsi jual adalah opsi yang memberikan hak (bukan kewajiban) kepada pemegangnya untuk menjual sejumlah tertentu dari instrumen yang menjadi dasar kontrak tersebut dengan jumlah tertentu pada waktu dan harga yang telah ditentukan.

Aset atau instrumen yang menjadi dasar sebuah kontrak opsi disebut underlying asset. Exercise price atau sering juga disebut strike price merupakan harga yang telah disepakati dalam kontrak opsi tersebut. Sedangkan expiration date atau dapat diartikan sebagai waktu jatuh tempo, merupakan waktu yang disepakati untuk transaksi opsi dapat dilaksanakan. Jika pemegang opsi melaksanakan haknya untuk membeli atau menjual, maka dikenal dengan istilah exercise.

Dalam perdagangan opsi dikenal Opsi tipe Eropa dan tipe Amerika. Opsi tipe Eropa adalah opsi yang dapat dilaksanakan pada saat jatuh tempo saja, sedangkan opsi tipe Amerika adalah opsi yang dapat dilaksanakan setiap saat hingga waktu jatuh tempo.

Salah satu opsi saham yang menarik perhatian dari banyak investor yaitu saham Apple.Apple merupakan sebuah perusahaan multinasional yang bergerak di bidang perancangan, pengembangan, dan penjualan barang-barang yang meliputi elektronik, perangkat lunak komputer serta komputer pribadi.

Di Bursa Efek Indonesia, kontrak opsi disebut sebagai kontrak opsi saham (KOS) yaitu adalah efek yang memuat hak beli pada opsi beli atau hak jual pada opsi jual atas saham induk (saham acuan) dalam jumlah dan harga pelaksanaan (strike price atau exercise price) tertentu serta berlaku dalam periode tertentu.

Hak beli pada opsi beli adalah suatu kontrak di mana pembeli (taker) KOS diberi hak oleh penjual (writer) KOS untuk membeli saham acuan (saham 
induk) dalam jumlah dan harga pelaksanaan serta berlaku dalam periode tertentu.Hak jual pada opsi jual adalah suatu kontrak di mana pembeli KOS diberi hak oleh penjual KOS untuk menjual saham acuan dalam jumlah dan harga pelaksanaan serta berlaku dalam jangka waktu tertentu.Strike pricel exercise price merupakan harga tebus atas suatu saham acuan KOS yang telah disepakati antara writer dan taker ketika terjadi perdagangan KOS yang dipertemukan dalam mesin perdagangan.

Ada hal yang perlu diperhitungkan pada perdagangan opsi saham agar para investor dapat menghasilkan return yang maksimal. Masalah yang umum terjadi pada perdagangan opsi saham yaitu kerugian yang dialami oleh investor.Salah satu faktor yang menyebabkan kerugian tersebut yaitu karena kurangnya pengetahuan tentang strategi yang akan digunakan untuk meminimalisir resiko dan memperoleh return yang maksimal.

Investor pemula yang tidak menggunakan strategi untuk menentukan harga opsi pasti akan sering mengalami kerugian dan akan cepat tenggelam dalam dunia investasi. Investor harus dapat menghitung harga dari opsi di mana harga opsi bisa dibeli atau dijual.Untuk mengatasi masalah tersebut, investor membutuhkan solusi untuk menghitung harga wajar dari opsi.

Salah satu solusi untuk menghitung harga wajar dari opsi yaitu model matematika untuk penentuan harga opsi. Model matematika yang lazim digunakan dan telah banyak diterima oleh para investor yaitu Model Black-Scholes. Model ini dikembangkan oleh Fisher Black dan Myron Scholes. Black dan Scholes mengasumsikan bahwa model ini menggunakan saham yang tidak memberikan dividen dan menggunakan lima variabel yang mempengaruhi harga opsi saham yaitu harga saham, strike price / exercise price yang ditetapkan, expiration date dari opsi, volatilitas harga saham yang diharapkan selama umur opsi, dan tingkat suku bunga jangka pendek selama umur opsi [3].

Bentuk model Black-Scholes berupa persamaan differensial parsial. Persamaan Black-Scholes untuk menentukan harga opsi adalah:

$\frac{\partial V}{\partial t}+r S \frac{\partial V}{\partial S}+\frac{1}{2} \sigma^{2} S^{2} \frac{\partial^{2} V}{\partial S^{2}}=r V$

Dibutuhkan suatu metode untuk menyelesaikannya, salah satunya metode beda hingga. Secara umum metode beda hingga adalah metode yang mudah digunakan dalam penyelesaian problem fisis yang mempunyai bentuk geometri yang teratur [4]. Pada prinsipnya metode beda hingga ini mengganti turunan yang ada pada persamaan diferensial dengan diskritisasi beda hingga berdasarkan deret Taylor.

Metode ini akan membuat pendekatan terhadap harga-harga yang tidak diketahui pada setiap titik secara diskrit. Dimulai dengan pemodelan dari suatu benda dengan membagi-bagi dalam grid atau kotak-kotak hitungan kecil yang secara keseluruhan masih memiliki sifat yang samadengan benda utuh sebelum terbagi menjadi bagian-bagian yang kecil.

Berdasarkan ekspansi deret Taylor, terdapat tiga skema beda hingga yang biasa digunakan dalam diskritisasi persamaan diferensial parsial, yaitu skema maju, skema mundur, dan skema tengah.

Skema maju

Pada skema maju, informasi pada titik hitung $i$ dihubungkan dengan titik hitung $i+1$ yang berada di depannya. 


\section{Eksakta Vol. 18 No. 2 Oktober 2017}

E-ISSN : 2549-7464, P-ISSN : 1411-3724

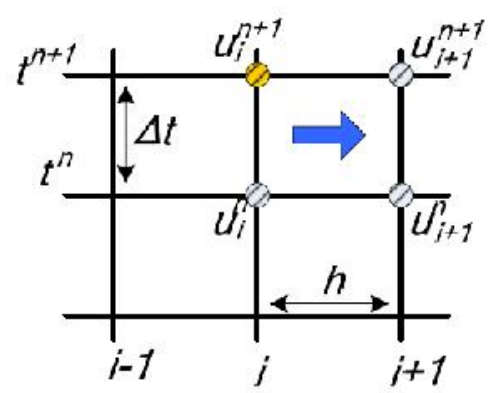

Gambar 1. SkemaMaju

Dengan menggunakan kisi beda hingga, maka skema maju biasa ditulis sebagai berikut,

Skema maju-ruang:

$\frac{\partial u}{\partial x}=\frac{u_{i+1}^{n}-u_{i}^{n}}{h} \operatorname{atau} \frac{\partial u}{\partial x}=\frac{u_{i+1}^{n+1}-u_{i}^{n+1}}{h}$

Skema maju-waktu:

$\frac{\partial u}{\partial t}=\frac{u_{i+1}^{n+1}-u_{i+1}^{n}}{\Delta t} \operatorname{atau} \frac{\partial u}{\partial t}=\frac{u_{i}^{n+1}-u_{i}^{n}}{\Delta t}$

Skema mundur

Pada skema mundur, informasi pada titik hitung $i$ dihubungkan dengan titik hitung $i-1$ yang berada di belakangnya.

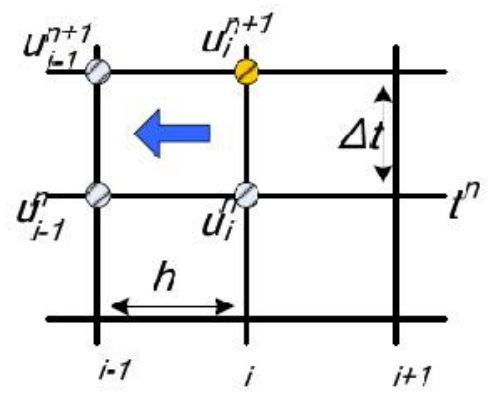

Gambar 2. Skema Mundur

Dengan menggunakan kisi beda hingga, maka skema mundur biasa ditulis sebagai berikut,

Skema mundur-ruang:

$\frac{\partial u}{\partial x}=\frac{u_{i}^{n}-u_{i-1}^{n}}{h} \operatorname{atau} \frac{\partial u}{\partial x}=\frac{u_{i}^{n+1}-u_{i-1}^{n+1}}{h}$

Skema mundur-waktu:

$\frac{\partial u}{\partial t}=\frac{u_{i-1}^{n+1}-u_{i=1}^{n}}{\Delta t} \operatorname{atau} \frac{\partial u}{\partial t}=\frac{u_{i}^{n+1}-u_{i}^{n}}{\Delta t}$

Skema tengah

Pada skema tengah, informasi pada titik hitung $i$ dihubungkan dengan titik hitung $i+1$ yang berada di depannya dan titik hitung $i-1$ yang berada di belakangnya.

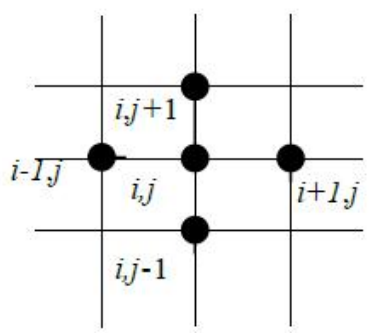

\section{Gambar3. Skema Tengah}

Skema tengah terhadap ruang:

(2) $\frac{\partial u}{\partial x}=\frac{u_{i+1}^{j}-u_{i-1}^{j}}{2 \Delta x}$

(3) Dalam hal ini, diterapkan pada saham, maka persamaan di atas menjadi:

$\frac{\partial u}{\partial S}=\frac{u_{i+1}^{j}-u_{i-1}^{j}}{2 \Delta S}$

dengan $S$ adalah harga saham.

Skema tengah terhadap waktu:

$\frac{\partial u}{\partial t}=\frac{u_{i}^{j+1}-u_{i}^{j-1}}{2 \Delta t}$

Metode Center Time Center Space (CTCS) merupakan salah satu metode beda hingga yang dapat menyelesaikan persamaan differensial parsial secara numerik. Metode CTCS digunakan untuk menyelesaikan model Black-Scholes karena harga saham dipengaruhi oleh waktu yang sebelumnya dan waktu yang akan datang.

Tujuan dari penelitian ini adalah untuk membantu para investor menggunakan

(4) metode beda hingga CTCS sebagai alat untuk mencari harga opsi tipe Eropa yang sebelumnya dibentuk dalam model BlackScholes. Agar para investor dapat menghitung harga dari opsi di mana opsi bisa dibeli atau dijual. 


\section{Eksakta Vol. 18 No. 2 Oktober 2017}

E-ISSN : 2549-7464, P-ISSN : 1411-3724

\section{METODE PENELITIAN}

Penelitian ini adalah penelitian terapan yang diawali dengan meninjau permasalahan, mengumpulkan bahan rujukan, mengaitkan teori-teori yang relevan dan diikuti dengan penerapannya. Jenis data pada penelitian ini adalah data sekunder, yaitu data yang dikumpulkan oleh pihak lain atau data yang telah tersedia. Populasi pada penelitian ini yaitu populasi berhingga, di mana populasinya adalah data harga penutupan saham Apple selama setahun. Pada penelitian ini sampel yang digunakan sama dengan populasi karena populasi yang digunakan hanya data dalam setahun.

Langkah-langkah yang dilakukan dalam teknik analisis data adalah sebagai berikut:

1. Untuk memperoleh formula dari model penentuan harga opsi tipe Eropa dengan model Black-Scholes menggunakan metode beda hingga CTCS, teknik analisis data mengikuti langkah-langkah sebagai berikut:

a. Mendiskritisasi model BlackScholes menggunakan metode beda hingga CTCS

b. Menyederhanakan model BlackScholes yang telah didiskritisasi sampai diperoleh formula dari model penentuan harga opsi tipe Eropa

2. Untuk mendapatkan harga opsi tipe Eropa pada saham Apple dengan model Black-Scholes menggunakan metode beda hingga CTCS, teknik analisis data mengikuti langkahlangkah sebagai berikut:

a. Mencari returnnya selama setahun terakhir

$$
R_{t}=\ln \left(\frac{S_{t}}{S_{t-1}}\right)
$$

dimana, $R_{t}$ : return
$S_{t}$ :harga saham saat waktu $t$

$S_{t-1}$ harga saham saat waktu

$t-1$

b. Mencari rata-rata returnnya

$$
\overline{R_{t}}=\frac{1}{n} \sum_{t=1}^{n} R_{t}
$$

dimana, $\overline{R_{t}}$ : rata-rata return

c. Mencari volatilitas harga saham

$$
\sigma=\sqrt{k \times \frac{\sum_{t=1}^{n}\left(R_{t}-\overline{R_{t}}\right)^{2}}{n-1}}
$$

dimana, $Q$ : volatilitas harga saham

$k$ :jumlah hari perdagangan dalam satu

tahun

d. Memasukkan nilai volatilitas ke dalam formula yang telah didapatkan

e. Menghitung harga opsi tipe Eropa dengan menggunakan aplikasi Matlab versi R2016b

\section{HASIL DAN PEMBAHASAN}

Model Black-Scholes merupakan model untuk menentukan harga opsi saham tipe Eropa. Model ini memiliki bentuk berupa persamaan diferensial parsial. Sehingga kita dapat menentukan nilai opsi beli dan opsi jual secara numerik, dengan menggunakan metode beda hingga CTCS. Diketahui persamaan diferensial parsial Black-Scholes berikut:

$$
\frac{\partial V}{\partial t}+r S \frac{\partial V}{\partial S}+\frac{1}{2} \sigma^{2} S^{2} \frac{\partial^{2} V}{\partial S^{2}}=r V
$$

dengan

$$
\begin{aligned}
& 0 \leq S \leq L \\
& 0 \leq t \leq T
\end{aligned}
$$

Diasumsikan bahwa harga saham tidak melewati harga tertinggi $L$, sehingga saham $S$ dibatasi dengan $0 \leq S \leq L$.

Persamaan

Black-Scholes ditransformasi agar dapat digunakan untuk menentukan harga opsi. Akan ditentukan syarat awal dan syarat batas untuk harga opsi beli dan opsi jual. 


\section{Eksakta Vol. 18 No. 2 Oktober $\mid 2017$}

E-ISSN : 2549-7464, P-ISSN : 1411-3724

Persamaan diferensial parsial BlackScholes yang telah ditransformasikan menjadi

$$
\frac{\partial V}{\partial \tau}-r S \frac{\partial V}{\partial S}-\frac{1}{2} \sigma^{2} S^{2} \frac{\partial^{2} V}{\partial S^{2}}+r V=0
$$

dengan

$$
\begin{aligned}
& 0 \leq S \leq L \\
& 0 \leq \tau \leq T
\end{aligned}
$$

Syarat awal:

\section{Opsi Beli}

$$
C(S, \tau=0)=\operatorname{maks}(S(0)-E, 0)=V(S, 0)
$$

\section{Opsi Jual}

$$
P(S, \tau=0)=\operatorname{maks}(E-S(0)), 0)=V(S, 0)
$$

Syarat batas:

Opsi Beli

Opsi Jual

$$
\begin{aligned}
& C(0, \tau)=0=V(0, \tau) \\
& C(L, \tau)=L=V(L, \tau)
\end{aligned}
$$

$$
\begin{gathered}
P(0, \tau)=E e^{-r \tau}=V(0, \tau) \\
P(L, \tau)=0=V(L, \tau)
\end{gathered}
$$

Interval $S$ dan $\tau$ akan di diskritisasi dengan panjang selang masing-masing adalah $h$ dan $k$, maka $h=\Delta s=\frac{L}{M}$ dan $k=\Delta t=\frac{T}{N}$, dengan $M$ dan $N$ masingmasing adalah jumlah titik selang pada interval $S$ dan $\tau$, dimana $i$ merupakan titik selang pada $S$ dan $n$ merupakan titik selang pada $\tau$.

Selanjutnya persamaan Black-Scholes akan dikonversi dengan metode beda hingga CTCS dititik $\left(S_{i}, \tau_{n}\right)=(i h, n k)$.

Dengan skema tengah terhadap waktu $\frac{\partial V}{\partial \tau}$, terhadap ruang (saham) $\frac{\partial V}{\partial S}$ dan $\frac{\partial^{2} V}{\partial S^{2}}$, akan disubstitusikan:

$S=i h$

$\frac{\partial V}{\partial \tau}=\frac{V_{i}^{n+1}-V_{i}^{n-1}}{2 k}$

$\frac{\partial V}{\partial S}=\frac{V_{i+1}^{n}-V_{i-1}^{n}}{2 h}$

$\frac{\partial^{2} V}{\partial S^{2}}=\frac{V_{i-1}^{n}-2 V_{i}^{n}+V_{i-1}^{n}}{h^{2}}$
Maka persamaan diferensial parsial Black-Scholes menggunakan metode beda hingga CTCS:

$$
\frac{V_{i}^{n+1}-V_{i}^{n-1}}{2 k}-r(i h)\left(\frac{V_{i+1}^{n}-V_{i-1}^{n}}{2 h}\right)-\frac{1}{2} \sigma^{2}(i h)^{2}
$$

Selanjutnya persamaan diatas dikalikan dengan $2 k$, maka didapat:

$$
\begin{aligned}
& V_{i}^{n+1}-V_{i}^{n-1}-\operatorname{rik}\left(V_{i+1}^{n}-V_{i-1}^{n}\right) \\
& -\sigma^{2} i^{2} k\left(V_{i-1}^{n} 2 V_{i}^{n}+V_{i+1}^{n}\right)+2 r k V_{i}^{n}=0
\end{aligned}
$$

Agar formula bisa digunakan untuk menghitung setiap nilai yang belum diketahui pada titik selang yang ada, maka disederhanakan bentuknya menjadi

$$
\begin{aligned}
& V_{i}^{n+1}=V_{i}^{n-1}-2 r k V_{i}^{n}+\operatorname{rik}\left(V_{i+1}^{n}-V_{i-1}^{n}\right) \\
& +\sigma^{2} i^{2} k\left(V_{i-1}^{n}-2 V_{i}^{n}+V_{i+1}^{n}\right)
\end{aligned}
$$

Persamaan diatas dapat ditulis alam bentuk sederhana:

$$
\boldsymbol{V}^{n+1}=V^{n-1}+W V^{n}+Z
$$

dengan

$$
V^{n+1}=\left[\begin{array}{c}
V_{1}^{n+1} \\
V_{2}^{n+1} \\
\vdots \\
V_{M-1}^{n+1}
\end{array}\right]
$$

$$
V^{n}=\left[\begin{array}{c}
V_{1}^{n} \\
V_{2}^{n} \\
\vdots \\
\vdots \\
V_{M-1}^{n}
\end{array}\right]
$$

$$
V^{n-1}=\left[\begin{array}{c}
V_{1}^{n-1} \\
V_{2}^{n-2} \\
\vdots \\
\vdots \\
V_{M-1}^{n-1}
\end{array}\right]
$$

$$
Z=\left[\begin{array}{c}
k\left(\sigma^{2} k-r\right) V_{0}^{n} \\
0 \\
\vdots \\
0 \\
k(M-1)\left(\sigma^{2}(M-1)+r\right) V_{M}^{n}
\end{array}\right]
$$




$$
W=(-2 r k) I+\sigma^{2} k D_{2} T_{2}+r k D_{1} T_{1}
$$

dimana,

$$
D_{\mathbf{1}}=\left[\begin{array}{ccccc}
1 & 0 & 0 & \cdots & 0 \\
0 & 2 & 0 & \cdots & \vdots \\
0 & 0 & 3 & \cdots & \vdots \\
\vdots & \vdots & \vdots & \ddots & \vdots \\
0 & \cdots & \cdots & \cdots & M-1
\end{array}\right]
$$$$
D_{2}=\left[\begin{array}{ccccc}
1^{2} & 0 & 0 & \cdots & 0 \\
0 & 2^{2} & 0 & \cdots & \vdots \\
0 & 0 & 3^{2} & \cdots & \vdots \\
\vdots & \vdots & \vdots & \ddots & \vdots \\
0 & \cdots & \cdots & \cdots & (M-1)^{2}
\end{array}\right]
$$$$
T_{1}=\left[\begin{array}{cccccc}
0 & 1 & 0 & \ldots & \ldots & 0 \\
-1 & 0 & 1 & \ldots & \ldots & \vdots \\
0 & -1 & 0 & \ldots & \ldots & \vdots \\
\vdots & \vdots & \vdots & \ddots & \cdots & \vdots \\
\vdots & \vdots & \vdots & \ldots & 0 & 1 \\
0 & \ldots & \ldots & \ldots & -1 & 0
\end{array}\right]
$$

$$
T_{2}=\left[\begin{array}{cccccc}
-2 & 1 & 0 & \ldots & \ldots & 0 \\
1 & -2 & 1 & \ldots & \ldots & \vdots \\
0 & 1 & -2 & \cdots & \ldots & \vdots \\
\vdots & \vdots & \vdots & \cdots & \ldots & \vdots \\
\vdots & \vdots & \vdots & \ldots & -2 & 1 \\
0 & \ldots & \ldots & \ldots & 1 & -2
\end{array}\right]
$$

Dengan $V_{0}^{n}$ dan $V_{M}^{n}$ adalah syarat batas nilai opsi.

Syarat batas untuk opsi beli:

$$
\begin{aligned}
& V_{0}^{n}=0 \\
& V_{M}^{n}=L
\end{aligned}
$$

Syarat batas untuk opsi jual:

$$
\begin{aligned}
& V_{0}^{n}=E e^{-r \tau} \\
& V_{M}^{n}=0
\end{aligned}
$$

Syarat awal untuk opsi beli dan jual tipe Eropa dalam bentuk matriks adalah: Syarat awal opsi beli

$$
V^{(0)}=\left[\begin{array}{c}
V_{1}^{0} \\
V_{2}^{0} \\
\vdots \\
V_{M-1}^{0}
\end{array}\right]
$$

dengan

$V_{i}^{0}=\operatorname{maks}\left(S_{i}-E, 0\right)=\operatorname{maks}(i h-$ $E, 0)$

Syarat awal opsi jual

dengan

$$
V^{(0)}=\left[\begin{array}{c}
V_{1}^{0} \\
V_{2}^{0} \\
\vdots \\
V_{M-1}^{0}
\end{array}\right]
$$

$V_{i}^{0}=\operatorname{maks}\left(E-S_{i}, 0\right)=\operatorname{maks}(E-$ $i h, 0$ )

Dalam aplikasi formula penentuan harga opsi dengan model BlackScholesmenggunakan metode beda hingga CTCS perlu diketahui nilai beberapa parameter, diantaranya harga saham awal/saat ini $\left(S_{0}\right)$, harga pelaksanaan/strike price/exercise price $(E)$, tingkat suku bunga $(r)$, waktu jatuh tempo $(T)$, banyak partisi harga saham $(M)$, banyak partisi waktu $(N)$ dan harga saham maksimum $(L)$ dimana $0 \leq S \leq L$. Untuk mendapatkan hasil yang baik, nilai $N$ yang dipilih adalah sebanyak hari waktu jatuh tempo $T$ dan untuk nilai $M$ adalah yang tidak terlalu besar saja sudah cukup.

Pada penelitian ini, aplikasi akan dilakukan dengan bantuan program Matlab Versi R2016b. Sehingga dibutuhkan sebuah algoritma untuk mencari solusi numeriknya. Algoritma untuk menentukan harga opsi dengan model Black-Scholesmenggunakan metode beda hingga CTCS adalah sebagai berikut:

1. 2.

nput nilai $S_{0}, L, E, N, M, T, \sigma, r$

emudian tentukan nilai $k=\frac{T}{N}$ dan $h=\frac{L}{M}$ 
E-ISSN : 2549-7464, P-ISSN : 1411-3724

3.

4.

entukan syarat awal untuk menentukan harga opsi

Syarat awal opsi beli

$V_{i}^{0}=\operatorname{maks}\left(S_{i}-E, 0\right)=\operatorname{maks}(i h-E, 0)$

Syarat awal opsi jual

$V_{i}^{\mathrm{D}}=\operatorname{maks}\left(E-S_{i}, 0\right)=\operatorname{maks}(E-i h, 0)$

entukan syarat batas untuk

menentukan harga opsi

Syarat batas untuk opsi beli:

$V_{0}^{n}=0$

$V_{M}^{n}=L$

Syarat batas untuk opsi jual:

$V_{0}^{n}=E e^{-r \tau}$

$V_{M}^{n}=0$

5. Hitung harga opsi pada masing-masing titik selang yang diinginkan dengan menggunakan formula yang telah didapatkan.

Aplikasi akan diterapkan pada saham Apple yang disimbolkan dengan AAPL dari bursa saham Amerika yaitu NASDAQ lalu memberikan rekomendasi untuk investor. Untuk mengestimasi volatilitas harga saham $(\sigma)$, akan digunakan data penutupan harga sahamApple (AAPL) yang dikumpulkan dalam frekuensi harian 5 Juli 2016 sampai 3 Juli 2017 dengan total pengamatan sebanyak 252 data. Data diambil dari www.finance.yahoo.com

Berdasarkan data penutupan harga saham AAPL, diestimasi volatilitas harga saham AAPL yaitu $\sigma=0.180090066 \approx 0.18=18 \%$. Harga saham AAPL di pasar pada tanggal 3 Juli $2017\left(S_{0}\right)$ yaitu $\$ 144.09$, dengan tingkat suku bunga Amerika $(r)$ pada saat itu yaitu $1.25 \%$, harga eksekusi (E) $\$ 140$ dan waktu jatuh tempo opsi saham tersebut 20 hari sampai tanggal 28 Juli 2017 ( $\tau=20 / 365)$. Maka harga opsi
$\mathrm{T}$ beli dan opsi jual dapat ditentukan dengan model Black Scholes menggunakan metode beda hingga CTCS yang telah diperoleh melalui bantuan aplikasi Matlab versi R2016b. Diperoleh harga opsi beli dan opsi jual tipe Eropa tanggal 28 Juli 2017 masing-masingnya adalah sebesar $\$ 5.2558$ untuk opsi beli dan $\$ 0.9734$ untuk opsi jual.

Harga opsi beli di pasar sebesar \$5.67(> \$5.2558), maka investor hendaknya menjual opsi beli. Hal ini dikarenakan opsi beli tersebut dalam keadaan overprice (menurut BS-CTCS), yaitu harga opsi beli di pasar lebih besar dari harga opsi beli yang ditentukan dengan model Black-Scholes menggunakan metode beda hingga CTCS.

Harga opsi jual di pasar sebesar \$1.32(>\$0.9734), maka investor hendaknya menjual opsi jual. Hal ini dikarenakan opsi jual tersebut dalam keadaan overprice (menurut BS-CTCS), yaitu harga opsi jual di pasar lebih besar dari harga opsi jual yang ditentukan dengan model Black-Scholes menggunakan metode beda hingga CTCS

\section{KESIMPULAN}

Formula penentuan harga opsi tipe Eropa dengan model Black-Scholes menggunakan metode beda hingga CTCS:

$$
V^{n+1}=V^{n-1}+W V^{n}+Z
$$

dimana, $\boldsymbol{V}$ :harga opsi

$$
W \text { :faktor-faktor }
$$

yangmempengaruhi harga

opsi saatini

$Z$ :faktor-faktor yang mempengaruhi harga

opsisaat opsi berada pada nilai batasnya

Dengan menggunakan formula penentuan harga opsi tipe Eropa pada saham Apple dengan model BlackScholes menggunakan metode beda 
hingga CTCS diperoleh harga opsi beli dan opsi jual tanggal 28 Juli 2017 masing-masingnya adalah sebesar $\$ 5.2558$ dan $\$ 0.9734$. Harga opsi beli di pasar sebesar \$5.67(> \$5.2558), maka investor hendaknya menjual opsi beli. Harga opsi jual di pasar sebesar \$1.32(>\$0.9734), maka investor hendaknya menjual opsi jual.

\section{REFERENSI}

[1] Tandelilin, E. 2010. Portofolio dan Investasi.Yogyakarta: Kanisius.
[2] Martalena dan Maya Melinda. 2011. Pengantar Pasar Modal. Yogyakarta: Andi Yogyakarta.

[3] Black, F dan Scholes, M. 1973. The Pricing of Options and Corporate Liabilities. The Journal of Political Economy.

[4] Li, Ronghua. 2010. Generalized Difference Methods for Differential Equations: Numerical Analysis of Finite Volume Methods. New York: Marcel Dekker. 